\title{
The Relationship between Natriuretic Peptide Precursor a Gene T2238C Polymorphism and Hypertension: A Meta-Analysis
}

\author{
Wenquan $\mathrm{Niu}^{1,2,3}$ \\ ${ }^{1}$ State Key Laboratory of Medical Genomics, Shanghai Key Laboratory of Vascular Biology, and Department of Hypertension, \\ Ruijin Hospital, Shanghai Jiao Tong University School of Medicine, Ruijin Second Road 197, Shanghai 200025, China \\ ${ }^{2}$ Laboratory of Vascular Biology, Institute of Health Sciences, Shanghai Institutes for Biological Sciences, Chinese Academy of Sciences, \\ Chongqing South Road 225, Shanghai 200025, China \\ ${ }^{3}$ Shanghai Institute of Hypertension, Shanghai Jiao Tong University School of Medicine, Ruijin Second Road 197, \\ Shanghai 200025, China
}

Correspondence should be addressed to Wenquan Niu, niuwenquan@yahoo.cn

Received 17 February 2011; Revised 20 March 2011; Accepted 14 April 2011

Academic Editor: Roberto Pontremoli

Copyright (C) 2011 Wenquan Niu. This is an open access article distributed under the Creative Commons Attribution License, which permits unrestricted use, distribution, and reproduction in any medium, provided the original work is properly cited.

\begin{abstract}
Single studies attempting to associate ANP gene T2238C (rs5065) polymorphism with hypertension have so far reported inconclusive results. We therefore aimed to evaluate this association via a meta-analysis. Data on 7 studies with a total of 4068 subjects were available and analyzed using the random-effects model with assessment of heterogeneity and publication bias. Overall comparison of $2238 \mathrm{C}$ with $2238 \mathrm{~T}$ yielded a $23 \%$ reduced, albeit nonsignificant, risk for hypertension (95\% CI: 0.38 $1.59 ; P=.485)$, while accompanying significant heterogeneity $\left(I^{2}=88.3 \%\right)$ and publication bias $(P=.051)$. Subgroup analysis by study design demonstrated opposite associations between population-based (OR $=0.33 ; 95 \% \mathrm{CI}: 0.13-0.80 ; P=.015)$ and hospital-based studies $(\mathrm{OR}=1.15 ; 95 \% \mathrm{CI}: 0.79-1.68 ; P=.454)$. Further meta-regression analysis exclusively indicated the significant influence of study design $(P=.042)$ on heterogeneity. Taken together, these findings support the notion that carriers of $2238 \mathrm{C}$ allele were at moderate decreased risk of developing hypertension, whereas study design was identified as a potentially significant source of between-study heterogeneity.
\end{abstract}

\section{Introduction}

Hypertension is a complex syndrome influenced by multiple genetic and environmental factors [1]. In view of some individuals being more susceptible to hypertension than others, it is essential to explain this interindividual differential susceptibility [2]. Although great hope was expressed in genome-wide association studies to unlock the genetic basis of hypertension, the results from such research, however, have told us little [3]. Given the limited power of single studies, one practicable strategy is to perform large metaanalyses to reliably evaluate the predetermined candidates in genetic association studies.

The gene encoding atrial natriuretic peptide (ANP, chromosome 1p36.21) is a logical candidate for involvement in the underlying cause of hypertension. The candidacy of ANP gene is well defined. Knockout mice deficient in one copy of ANP gene was associated with salt-sensitive hypertension [4]. In contrast, overexpression of ANP gene via gene therapy in hypertensive mice had lowered systolic blood pressure [5]. These findings therefore encourage the search for human genetic polymorphisms that affect the ANP functionality. A large panel of ANP gene polymorphisms have been identified; in particular, an exonic polymorphism T2238C (rs5065) ranks high in association with hypertension; however, the results in some individually underpowered studies are often irreproducible $[6,7]$. To derive a more precise estimation, we therefore meta-analyzed the association of ANP gene T2238C polymorphism with occurrence of hypertension from both English and Chinese literature, while addressing between-study heterogeneity and publication bias. 


\section{Methods}

2.1. Search Strategy for Identification of Studies. We searched PubMed and EMBASE, as well as China Biological Medicine (http://sinomed.imicams.ac.cn/index.jsp) and Wanfang (http://www.wanfangdata.com.cn) databases for articles published before 10 February 2011 using the Boolean combinations of keywords (atrial natriuretic peptide OR natriuretic peptide precursor A OR ANP or NPPA) AND (hypertension OR blood pressure) AND (polymorphism OR allele $O R$ genotype $O R$ variant $O R$ variation). Search results were limited to human populations and articles written in both English and Chinese languages. The full text of the retrieved articles was scrutinized to decide whether information on the topic of interest was included. Reference lists of these retrieved articles and systematic reviews were also checked to determine whether citations of articles were not initially identified. For these articles involving more than one geographic or ethnic heterogeneous groups, each group was treated separately.

2.2. Inclusion/Exclusion Criteria. Articles were included in this meta-analysis if they examined the hypothesis that ANP gene T2238C polymorphism was associated with hypertension, if they followed a case-control or cross-sectional study design, and if they provided sufficient information on T2238C genotype counts between hypertensive patients and controls for determining an estimate of odds ratio (OR) and its corresponding 95\% confidence interval (CI).

Hypertension was defined as systolic blood pressure equal to or above $140 \mathrm{mmHg}$ or diastolic blood pressure equal to or above $90 \mathrm{mmHg}$ or previous treatment with antihypertensive drugs. Studies evaluating secondary hypertension or other types of monogenic hypertension were excluded. Where there were multiple articles from the same study population, the most complete and recent results were extracted.

2.3. Extracted Information. The following characteristics were extracted independently and entered into separate databases by Wenquan Niu and Yue Qi (who is an assistant researcher in Beijing Institute of Heart, Lung \& Blood Vessel Diseases, Anzhen Hospital) from each qualified study: first author's last name, publication date, population ethnicity, study design, diagnostic criteria, baseline characteristics of the study population (such as age, gender, and body mass index), and the T2238C genotype counts in patients and controls. For consistency, quantitative variables expressed as mean \pm standard error (SE) were converted to mean \pm standard deviation (SD). Any encountered discrepancies were adjudicated by a discussion, and a consensus was reached.

2.4. Statistical Analysis. The random-effects model using the DerSimonian \& Laird method was implemented to bring the individual effect-size estimates together, and the estimate of heterogeneity was taken from the Mantel-Haenszel model [13]. Unadjusted OR and 95\% CI were used to compare genetic contrasts between patients and controls.
Between-study heterogeneity was assessed by the inconsistency index $I^{2}$ statistic (ranging from 0 to $100 \%$ ), which was documented for the percentage of the observed betweenstudy variability due to heterogeneity rather than chance, with higher values suggesting the existence of heterogeneity $[14,15]$. In the case of between-study heterogeneity, we examined the study characteristics that can stratify the studies into subgroups with homogeneous effects. In addition, to estimate the extent to which one or more covariates explain heterogeneity, meta-regression, as an extension to randomeffects meta-analysis, was employed.

Cumulative meta-analysis was conducted to identify the influence of the first published study on the subsequent publications, and the evolution of the combined estimates over time according to the ascending date of publication. To identify potentially influential studies, sensitivity analysis was undertaken by removing an individual study each time to check whether any of these estimates can bias the overall estimate.

The funnel plots and Egger regression asymmetry test were used to assess publication bias. Egger's test can detect funnel plot asymmetry by determining whether the intercept deviates significantly from zero in a regression of the standardized effect estimates against their precision.

Probability less than 0.05 was judged significant with the exception of the $I^{2}$ statistic and Egger's test, where a significance level of less than 0.1 was chosen. Data management and statistical analyses were performed using STATA version 11.0 for Windows.

\section{Results}

3.1. Search Results. Based on our search strategy, the primary screening produced 25 potentially relevant articles, of which 7 met the inclusion criteria with an attempt to evaluate the association of ANP gene T2238C polymorphism with the occurrence of hypertension [6-12]. A total of 2041 hypertensive patients and 2027 controls were analyzed. Of these 7 articles, three [6-8] were published in English and four in Chinese language [9-12]. Five out of 7 articles were conducted in Asians (four in Chinese [9-12] and one in Japanese [8]). The detailed selection process is presented in Figure 1.

3.2. Study Characteristics. The baseline characteristics of qualified studies are presented in Table 1. Overall 2238C allele frequency was $4.19 \%$ in patients and $8.14 \%$ in controls with the highest frequency noted in an African-American population (41.67\% and 38.64\%) [6] and the lowest frequency in a Chinese Han population $(0.92 \%$ and $0.82 \%)$ [10]. Genotyping for T2238C polymorphism across all studies, except two using the gene chip technology $[9,12]$ and one using TaqMan assay [10], was conducted using polymerase chain reaction-restriction fragment length polymorphism (PCR-RFLP) followed by enzyme ScaI digestion.

3.3. Overall Analysis. Considering the low frequency of 2238CC genotype, we only assessed the association of 2238C allele (relative to $2238 \mathrm{~T}$ allele) with hypertension risk in this 


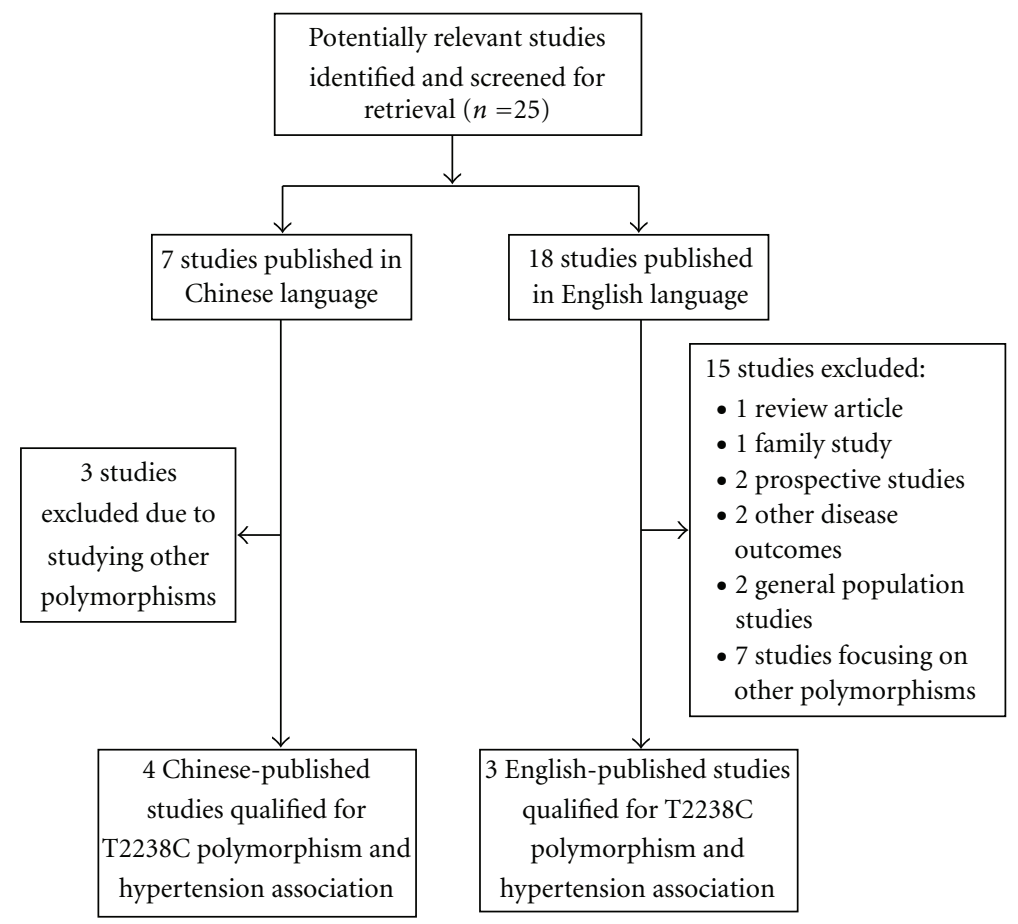

FIGURE 1: Flow diagram of search strategy and study selection.

meta-analysis. Overall speaking, comparison of allele $2238 \mathrm{C}$ with $2238 \mathrm{~T}$ generated a $23 \%$ reduced, albeit nonsignificant, risk for hypertension (95\% CI: 0.38-1.59; $P=.485$ ) (Figure 2). Meanwhile, there was strong evidence of betweenstudy heterogeneity $\left(I^{2}=88.3 \%, P<.0005\right)$ and high possibility of publication bias as reflected by the suggestive asymmetry of funnel plot (Figure 3 ) and the Egger's test $(P=.051)$.

3.4. Cumulative and Influential Analyses. In the cumulative meta-analysis, there was no evidence suggesting the first published study that reported a potentially significant result and then trigged the subsequent replication (data not shown). However, the influential analysis revealed that there was one study in a Kazakh Chinese population [11] influencing the overall results significantly (Figure 2). When this most influential study was removed, the overall estimate was strongly attenuated with $\mathrm{OR}$ approaching the unity $(\mathrm{OR}=$ 0.97; 95\% CI: $0.62-1.51 ; P=.897)$. Likewise, betweenstudy heterogeneity was remarkably reduced $\left(I^{2}=51.2 \%\right.$, $P=.069)$, and there was a low probability of publication bias $(P=.479)$ (Figure 3$)$.

3.5. Subgroup Analysis. Considering the significance of heterogeneity, we considered as a better choice to try investigating its sources by conducting subgroup analysis in characteristic-homogeneous groups. To evaluate the possible effect of study design on the variability of overall estimates, studies were divided into population-based and hospitalbased studies, and importantly the magnitude of association in population-based studies was strikingly reinforced with the $2238 \mathrm{C}$ allele conferring a significant protective effect on hypertension $(\mathrm{OR}=0.33 ; 95 \% \mathrm{CI}: 0.13-0.80 ; P=.015)$, whereas this effect was reversed in hospital-based studies with no attainable significance $(\mathrm{OR}=1.15$; 95\% CI: $0.79-$ $1.68 ; P=.454$ ) (Figure 4(a)).

Further subgroup analysis by ethnicity suggested heterogeneous associations of T2238C polymorphism with hypertension, by showing a suggestive risk effect of $2238 \mathrm{C}$ allele in Blacks ( $\mathrm{OR}=1.13 ; P=.66)$, a significant protective effect in Whites $(\mathrm{OR}=0.53 ; P=.019)$, and a moderate protective effect in Asians $(\mathrm{OR}=0.79 ; P=.663$ ) (Figure 4(b)).

Because sample size of study is also a major factor affecting the reliability, we therefore used an additional strategy to estimate the effect by grouping only those large association studies with an arbitrary cutoff of 500 individuals. Two out of seven studies had sample sizes greater than 500 and conferred a 53\% reduced risk for $2238 \mathrm{C}$ allele relative to 2238T allele (95\% CI: $0.09-2.45 ; P=.374$ ), accompanying high between-study heterogeneity $\left(I^{2}=94.7 \%, P<.0005\right)$ (Figure 4(c)).

3.6. Meta-Regression Analysis. To further account for between-study heterogeneity within a multivariable framework, we performed meta-regression by incorporating various study-level covariates including averaged levels of age, male percent, and body mass index (BMI) between patients and controls, as well as study design and ethnicity altogether, and we interestingly and exclusively observed that study design was a significant source of between-study heterogeneity $(P=.042)$. 
TABLE 1: The baseline characteristics of all qualified studies in this meta-analysis.

\begin{tabular}{|c|c|c|c|c|c|c|c|c|c|c|c|}
\hline \multirow{2}{*}{ Author, ref and year } & \multirow{2}{*}{$\begin{array}{c}\text { Country } \\
\text { (Ethnicity) }\end{array}$} & \multirow{2}{*}{ Design } & \multirow{2}{*}{ Status } & \multirow{2}{*}{ Age, year } & \multirow{2}{*}{$\begin{array}{l}\text { Gender, } \\
\mathrm{M}(\%)\end{array}$} & \multirow{2}{*}{ BMI, kg/m² } & \multirow{2}{*}{$\begin{array}{l}\text { SBP, } \\
\mathrm{mmHg}\end{array}$} & \multirow{2}{*}{$\begin{array}{c}\text { DBP, } \\
\mathrm{mmHg}\end{array}$} & \multicolumn{3}{|c|}{ T2238C } \\
\hline & & & & & & & & & $\mathrm{TT}$ & $\mathrm{TC}$ & $\mathrm{CC}$ \\
\hline \multirow{2}{*}{$\begin{array}{l}\text { Rahmutula et al. [8] } \\
2001\end{array}$} & \multirow[t]{2}{*}{$\begin{array}{c}\text { Japan } \\
\text { (Japanese) }\end{array}$} & \multirow[t]{2}{*}{$\mathrm{H}-\mathrm{B}$} & Cases & $50(8)$ & 65.67 & $24.7(3.7)$ & $\begin{array}{l}170 \\
(20)\end{array}$ & $\begin{array}{l}105 \\
(12)\end{array}$ & 222 & 11 & 0 \\
\hline & & & Controls & $49(10)$ & 69.95 & $23(3.1)$ & $\begin{array}{l}115 \\
(13) \\
\end{array}$ & $\begin{array}{c}70 \\
(10) \\
\end{array}$ & 200 & 13 & 0 \\
\hline \multirow{2}{*}{$\begin{array}{l}\text { Nannipier et al. [7] } \\
2001\end{array}$} & \multirow[t]{2}{*}{$\begin{array}{l}\text { Europe } \\
\text { (White) }\end{array}$} & \multirow[t]{2}{*}{ P-B } & Cases & $56(11)$ & 47.93 & $25.9(2.8)$ & $\begin{array}{l}141 \\
(15)\end{array}$ & $\begin{array}{c}86 \\
(10)\end{array}$ & 95 & 26 & 0 \\
\hline & & & Controls & $41(10)$ & 47.62 & $24.4(3.2)$ & $\begin{array}{l}122 \\
(14) \\
\end{array}$ & $\begin{array}{l}78 \\
(8) \\
\end{array}$ & 67 & 37 & 1 \\
\hline \multirow{2}{*}{$\begin{array}{l}\text { Rutledge et al. [6] } \\
1995\end{array}$} & \multirow[t]{2}{*}{$\begin{array}{c}\text { US } \\
\text { (Black) }\end{array}$} & \multirow[t]{2}{*}{$\mathrm{H}-\mathrm{B}$} & Cases & $44.7(15.2)$ & 56.70 & - $^{*}$ & - & - & 17 & 36 & 7 \\
\hline & & & Controls & $44.8(14.7)$ & 65.90 & - & - & - & 19 & 16 & 9 \\
\hline \multirow{2}{*}{$\begin{array}{l}\text { Hu et al. [9] } \\
2010\end{array}$} & \multirow[t]{2}{*}{$\begin{array}{c}\text { China } \\
\text { (Han } \\
\text { Chinese) }\end{array}$} & \multirow[t]{2}{*}{$\mathrm{H}-\mathrm{B}$} & Cases & $57.71(9.97)$ & 48 & $23.79(2.99)$ & $\begin{array}{l}171.47 \\
(13.01)\end{array}$ & $\begin{array}{l}100.74 \\
(8.34)\end{array}$ & 97 & 3 & 0 \\
\hline & & & Controls & $55.05(10.64)$ & 43.30 & $24.24(4.50)$ & $\begin{array}{l}115.66 \\
(10.99) \\
\end{array}$ & $\begin{array}{l}73.49 \\
(8.15) \\
\end{array}$ & 93 & 4 & 0 \\
\hline \multirow{2}{*}{$\begin{array}{l}\text { Tian and Cheng [10] } \\
2010\end{array}$} & \multirow[t]{2}{*}{$\begin{array}{c}\text { China } \\
\text { (Han } \\
\text { Chinese) }\end{array}$} & \multirow[t]{2}{*}{$\mathrm{H}-\mathrm{B}$} & Cases & $59.89(9.81)$ & 72.00 & $24.33(3.69)$ & $\begin{array}{l}170.95 \\
(23.86)\end{array}$ & $\begin{array}{l}105.67 \\
(14.35)\end{array}$ & 960 & 14 & 2 \\
\hline & & & Controls & $59.68(9.78)$ & 70.00 & $23.31(3.21)$ & $\begin{array}{l}115.59 \\
(20.85) \\
\end{array}$ & $\begin{array}{c}70.20 \\
(11.00) \\
\end{array}$ & 962 & 12 & 2 \\
\hline \multirow{2}{*}{$\begin{array}{l}\text { Li et al. [11] } \\
2005\end{array}$} & \multirow[t]{2}{*}{$\begin{array}{c}\text { China } \\
\text { (Kazakh } \\
\text { Chinese) }\end{array}$} & \multirow[t]{2}{*}{ P-B } & Cases & $46.80(7.82)$ & 40.89 & $26.27(4.84)$ & $\begin{array}{l}168.53 \\
(24.72)\end{array}$ & $\begin{array}{l}104.51 \\
(15.02)\end{array}$ & 273 & 35 & 5 \\
\hline & & & Controls & $45.75(8.63)$ & 45.37 & $25.16(5.63)$ & $\begin{array}{l}117.39 \\
(11.36) \\
\end{array}$ & $\begin{array}{l}73.95 \\
(8.58) \\
\end{array}$ & 205 & 187 & 16 \\
\hline \multirow{2}{*}{$\begin{array}{l}\text { Wang and Mao [12] } \\
2009\end{array}$} & $\begin{array}{c}\text { China } \\
\text { (Han } \\
\text { Chinese) }\end{array}$ & \multirow[t]{2}{*}{ H-B } & Cases & $68.61(12.76)$ & 57.14 & - & - & - & 220 & 18 & 0 \\
\hline & & & Controls & $68.45(13.19)$ & 59.27 & - & - & 一 & 179 & 5 & 0 \\
\hline
\end{tabular}

Ref: reference number; P-B: population-based design; H-B: hospital-based design; M (\%): male (percent); BMI: body mass index; SBP: systolic blood pressure; DBP: diastolic blood pressure. ${ }^{*}$ Information not available. Data are expressed as mean (SD) unless otherwise indicated.

\section{Discussion}

This study, including 4068 subjects, to our knowledge, is the first meta-analysis examining the relationship between ANP gene T2238C polymorphism and hypertension. Although some statistical biases could not be eliminated, our results suggested that carriers of 2238C allele were at moderate decreased risk of developing hypertension, whereas study design was identified as a potentially significant source of between-study heterogeneity by both subgroup and metaregression analyses, indicating the robustness of our results.

Genetic heterogeneity is an inevitable problem in any disease identification strategy [16]. As shown in this study, we speculated that ANP gene T2238C polymorphism might have diverse roles in different ethnic populations. On one hand, striking differences were noted in terms of mutant 2238C allele frequency between African-Americans and Asians, with the former almost tenfold higher than the latter, suggesting that different genetic backgrounds may cause this discrepancy, or different populations may have different linkage disequilibrium patterns. A polymorphism may be in close linkage with another nearby causal variant in one ethnic population but not in another [17]. The ANP gene T2238C polymorphism may be in close linkage with different nearby causal variants in different populations. On the other hand, in our subgroup analysis, T2238C polymorphism showed significant heterogeneous associations with hypertension across different ethnic groups, with 2238C allele in AfricanAmericans being completely at odds with that in Whites and Asians, suggesting that this polymorphism might have a multifunctional role in the pathogenesis of hypertension or interact with other genetic and environmental factors. However, considering the relative small sample sizes in each group, we suggest that confirmation in large, well-designed studies is critical.

Besides the disturbing influence of ethnicity in this metaanalysis, it should still be treated with caution because of different study designs. Interestingly, we observed that magnitude of association was reversed in population-based studies relative to in hospital-based studies although no significance was identified for the latter. Regarding this point, we agree that control for population stratification remains 


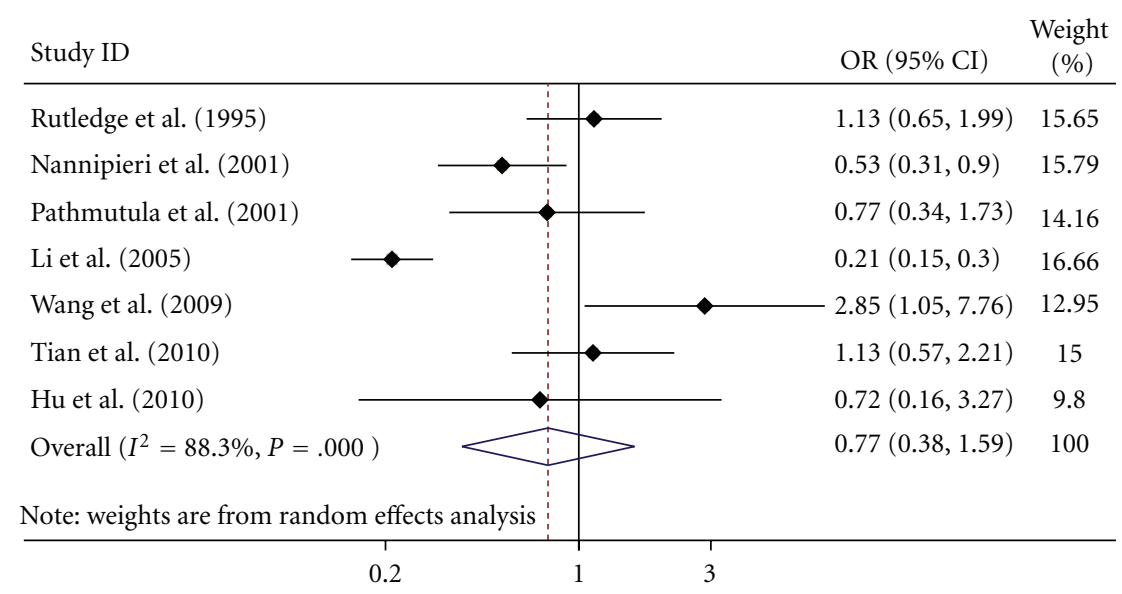

(a)

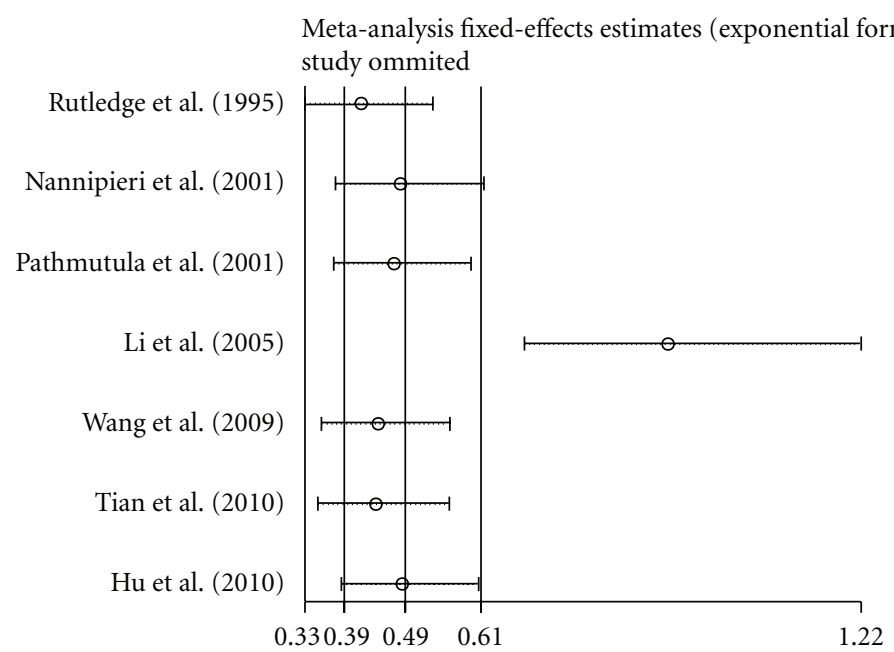

(b)

FigURE 2: Overall risk estimate of ANP gene 2238C versus 2238T allele for hypertension (a) and the presentation of its influential analysis (b).

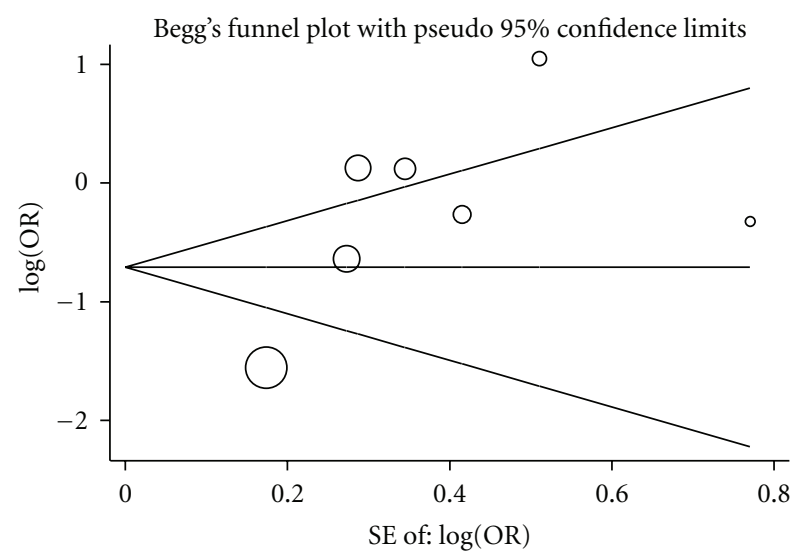

(a)

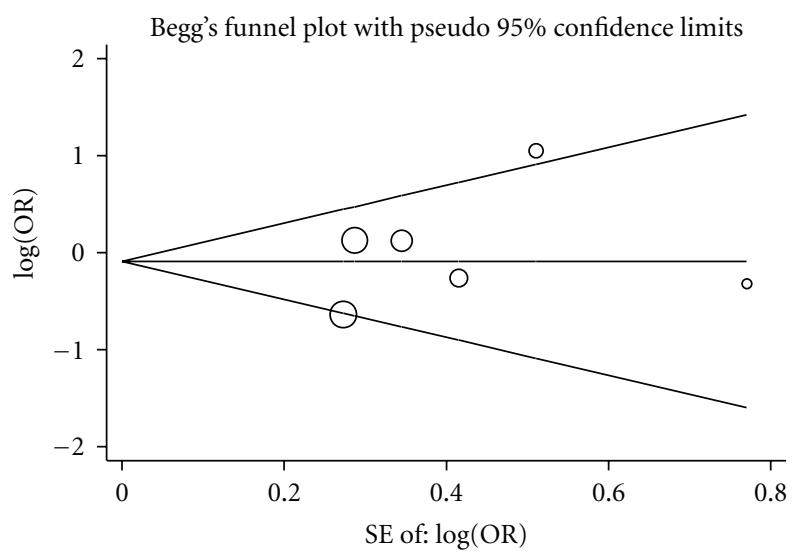

(b)

FIGURE 3: Funnel plots for studies investigating the effect of ANP gene T2238C polymorphism on the risk of hypertension in overall allelic model (a) and after excluding the most influential study (b). Vertical axis represents the log of OR; horizontal axis represents the SE of $\log (\mathrm{OR})$. Funnel plots are drawn with $95 \%$ confidence limits. OR, odds ratio; SE, standard error. The graphic symbols represent the data in the plot sized proportional to the inverse variance. 


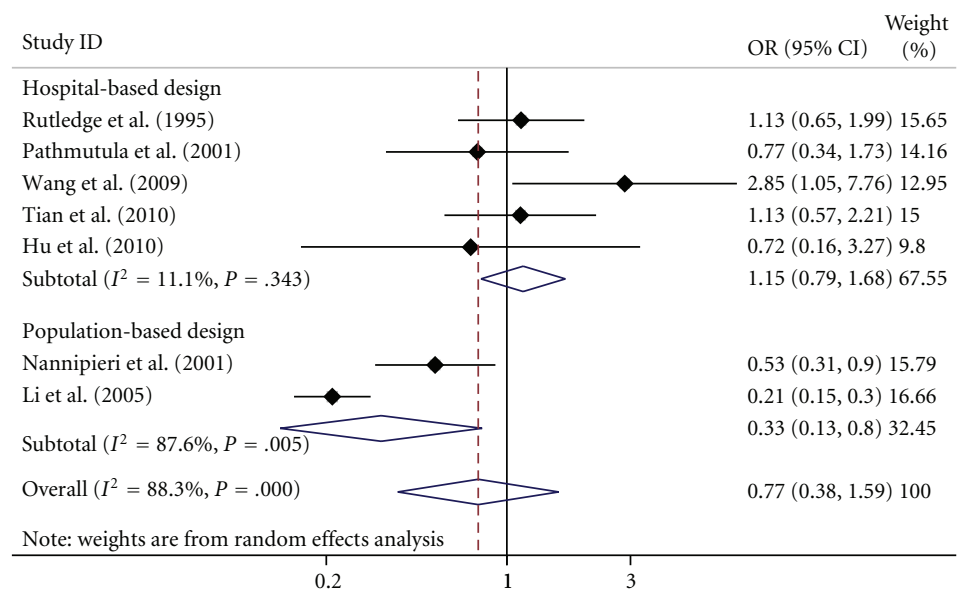

(a)

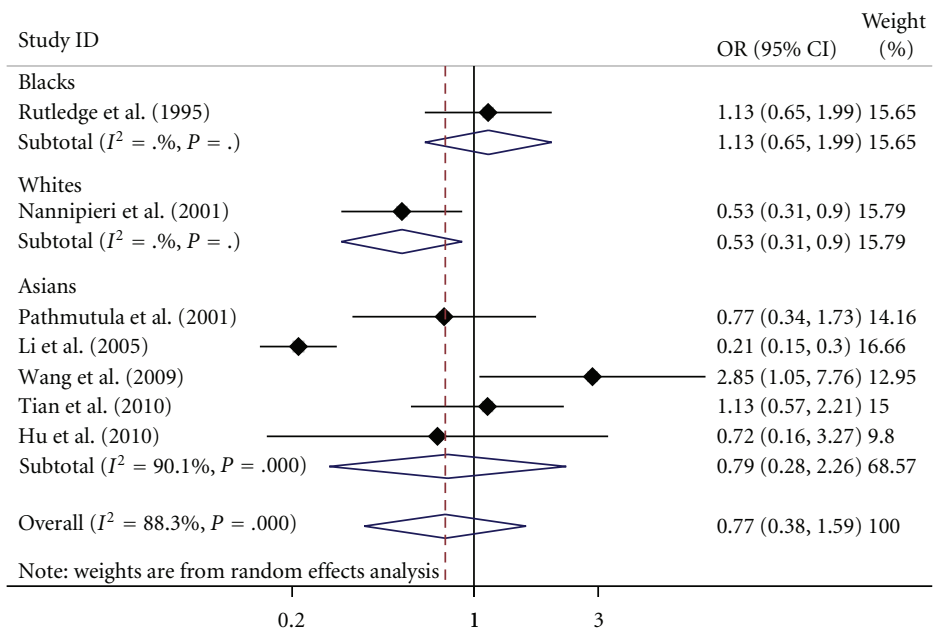

(b)

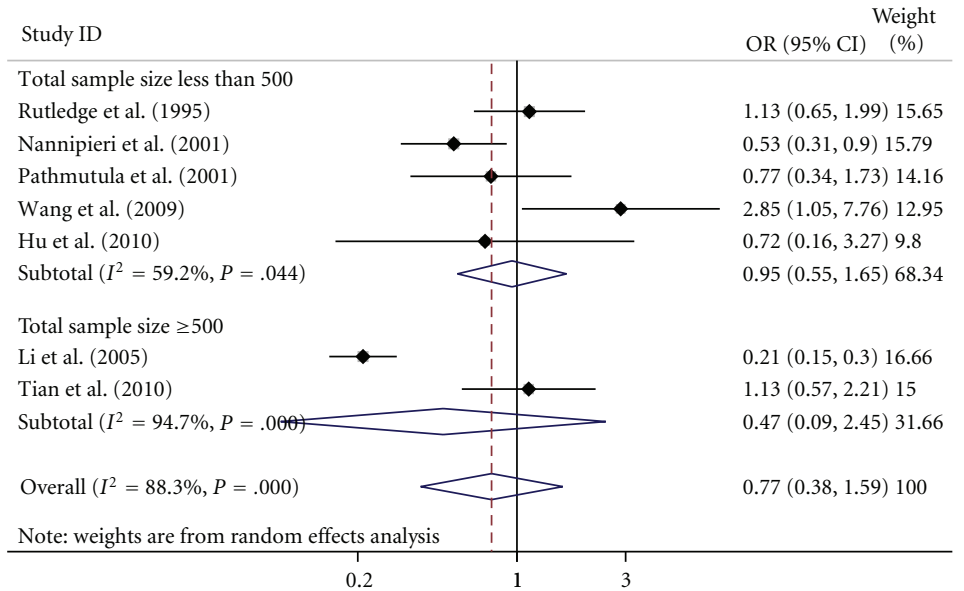

(c)

Figure 4: Subgroup analysis of ANP gene T2238C polymorphism with hypertension by study design (a), ethnicity (b), and sample size (cutoff: 500 individuals) (c) in the allelic model. 
an important consideration in hospital-based studies [18], because in this meta-analysis, most studies have recruited subjects from only one hospital, and thus there might be a narrow socioeconomic profile for both patients and controls. Moreover, in hospital-based studies, poor comparability between cases and controls might exert a confounding effect on the true association in light of a regional specialty for the disease under study and the differential hospitalization rates between cases and controls [19]. In contrast, subjects drawn from community or a fixed group might be representative of the true population, leading us to believe that results from population-based studies might hold the water. Considering the wider confidence intervals of estimates and small sample sizes in population-based studies, more studies are required to quantify this effect size reliably.

Despite the clear strengths of our study including relatively large sample sizes and robustness of statistical analyses, interpretation of our current study, however, should be viewed in light of several technical limitations. Because only published studies were retrieved in this meta-analysis and the "grey" literature (articles in languages other than English and Chinese) was not included, publication bias might be possible, even though our funnel plots and statistical tests did not show it. In addition, most studies in this meta-analysis have recruited subjects aged $\geq 50$ years, for whom environmental factors are likely to contribute more prominently than the genetic component to the development of hypertension [20], suggesting that large association studies in a younger population of hypertensive subjects are of added interest. Moreover, the single-locus-based nature of metaanalysis precluded the possibility of gene-gene and geneenvironment interactions, as well as haplotype-based effects, suggesting that additional studies assessing these aspects will be necessary. Furthermore, we only centered on ANP gene T2238C polymorphism and did not cover other candidate genes or polymorphisms. It seems likely that the T2238C polymorphism individually makes a moderate contribution to risk prediction in hypertensive subjects, but whether this polymorphism integrated with other risk factors will enhance the prediction requires additional research. Thus, the jury must refrain from drawing a conclusion until large, well-performed studies confirm or refuse our results.

Taken together, we expand previous single studies on hypertension by suggesting that ANP gene T2238C polymorphism might contribute to the occurrence of hypertension, especially in population-based studies. Also our observations leave open the question regarding the heterogeneous effect of $2238 \mathrm{C}$ allele across different ethnic populations. Further genetic and functional studies are warranted to elucidate the relationship between T2238C polymorphism and hypertension, and mechanisms of the ANP gene and hypertension.

\section{Acknowledgments}

This work was supported by the SMC Excellent Young Faculty Award of Shanghai Jiao Tong University, Youth Foundation of Shanghai Municipal Health Bureau (2010Y050), Shanghai "Chen Guang" Project (09CG12), the Natural Science Foundation of Shanghai (09ZR1426200), and the National Science Foundation for Young Scientists of China (30900808).

\section{References}

[1] W. Niu, S. Wu, YI. Zhang et al., "Validation of genetic association in apelin-AGTRL1 system with hypertension in a larger Han Chinese population," Journal of Hypertension, vol. 28, no. 9, pp. 1854-1861, 2010.

[2] W. Niu, Y. Qi, S. Hou, X. Zhai, W. Zhou, and C. Qiu, "Haplotype-based association of the renin-angiotensinaldosterone system genes polymorphisms with essential hypertension among Han Chinese: the Fangshan study," Journal of Hypertension, vol. 27, no. 7, pp. 1384-1391, 2009.

[3] T. W. Kurtz, "Genome-wide association studies will unlock the genetic basis of hypertension: con side of the argument," Hypertension, vol. 56, no. 6, pp. 1021-1025, 2010.

[4] S. W. M. John, J. H. Krege, P. M. Oliver et al., "Genetic decreases in atrial natriuretic peptide and salt-sensitive hypertension," Science, vol. 267, no. 5198, pp. 679-681, 1995.

[5] K. J. Schillinger, S. Y. Tsai, G. E. Taffet et al., "Regulatable atrial natriuretic peptide gene therapy for hypertension," Proceedings of the National Academy of Sciences of the United States of America, vol. 102, no. 39, pp. 13789-13794, 2005.

[6] D. R. Rutledge, Y. Sun, and E. A. Ross, "Polymorphisms within the atrial natriuretic peptide gene in essential hypertension," Journal of Hypertension, vol. 13, no. 9, pp. 953-955, 1995.

[7] M. Nannipieri, M. Manganiello, A. Pezzatini, A. De Bellis, G. Seghieri, and E. Ferrannini, "Polymorphisms in the hANP (human atrial natriuretic peptide) gene, albuminuria, and hypertension," Hypertension, vol. 37, no. 6, pp. 1416-1422, 2001.

[8] D. Rahmutula, T. Nakayama, M. Soma et al., "Association study between the variants of the human ANP gene and essential hypertension," Hypertension Research, vol. 24, no. 3, pp. 291-294, 2001.

[9] D. Hu, J. Shao, X. Zhao et al., "Association between the polymorphisms of candidate gene ANP/NPR-C and essential hypertension," Journal of Medical Research, vol. 39, pp. 72-75, 2010.

[10] C. Tian and L. Cheng, "Association of polymorphisms in atrial and brain natriuretic peptide gene with essential hypertension," Acta Universitatis Medicinae Tongji, vol. 39, pp. 13-17, 2010.

[11] N. Li, Y. Zhang, T. Li, and L. Zhou, "The relationship between ANP gene T2238C polymorphism and essential hypertension in Xinjiang Kazakans," Journal of Clinical Cardiology (China), vol. 21, pp. 513-515, 2005.

[12] Z. Wang and Y. J. Mao, "The relationship between endothelial atrial natriuretic peptide and type- $\mathrm{C}$ natriuretic peptide receptor gene polymorphisms and essential hypertension in elderly," Journal of Clinical Internal Medicine, vol. 26, pp. 620$622,2009$.

[13] L. D. Cohn and B. J. Decker, "How meta-analysis increases statistical power," Psychological Methods, vol. 8, no. 3, pp. 243253, 2003.

[14] J. P. T. Higgins and S. G. Thompson, "Quantifying heterogeneity in a meta-analysis," Statistics in Medicine, vol. 21, no. 11, pp. 1539-1558, 2002.

[15] J. P. T. Higgins, S. G. Thompson, J. J. Deeks, and D. G. Altman, "Measuring inconsistency in meta-analyses," British Medical Journal, vol. 327, no. 7414, pp. 557-560, 2003. 
[16] K. Hemminki, J. Lorenzo Bermejo, and A. Försti, “The balance between heritable and environmental aetiology of human disease," Nature Reviews Genetics, vol. 7, no. 12, pp. 958-965, 2006.

[17] K. Yu, J. Zhang, J. Zhang et al., "Methionine synthase A2756G polymorphism and cancer risk: a meta-analysis," European Journal of Human Genetics, vol. 18, no. 3, pp. 370-378, 2010.

[18] G. Salanti, S. Sanderson, and J. P.T. Higgins, "Obstacles and opportunities in meta-analysis of genetic association studies," Genetics in Medicine, vol. 7, no. 1, pp. 13-20, 2005.

[19] A. Ruano-Ravina, M. Pérez-Ríos, and J. Miguel Barros-Dios, "Population-based versus hospital-based controls: are they comparable?” Gaceta Sanitaria, vol. 22, no. 6, pp. 609-613, 2008.

[20] T. V. Pereira, A. C. F. Nunes, M. Rudnicki, Y. Yamada, A. C. Pereira, and J. E. Krieger, "Meta-analysis of the association of 4 angiotensinogen polymorphisms with essential hypertension: a role beyond M235T?" Hypertension, vol. 51, no. 3, pp. 778783,2008 . 


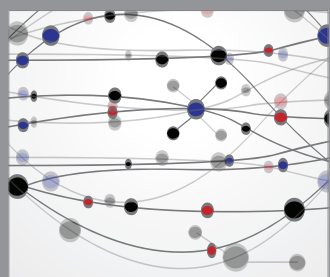

The Scientific World Journal
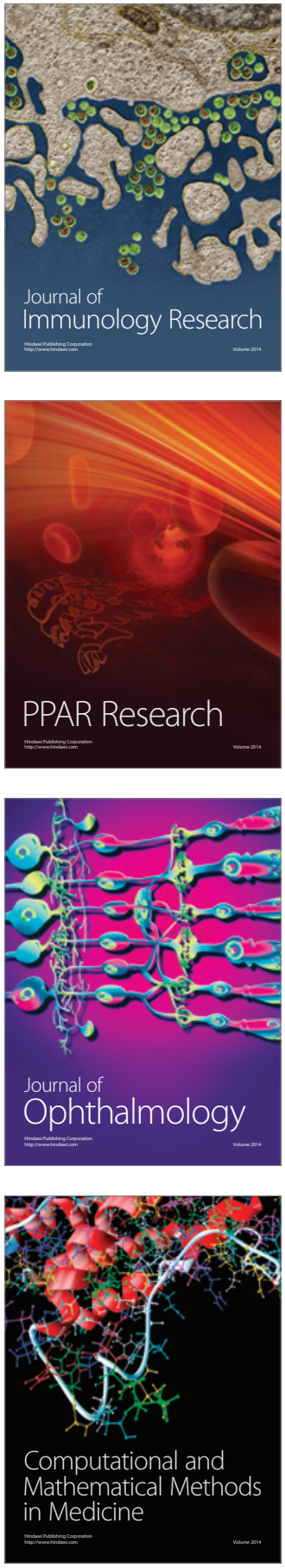

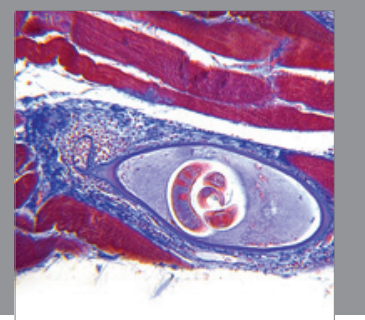

Gastroenterology

Research and Practice
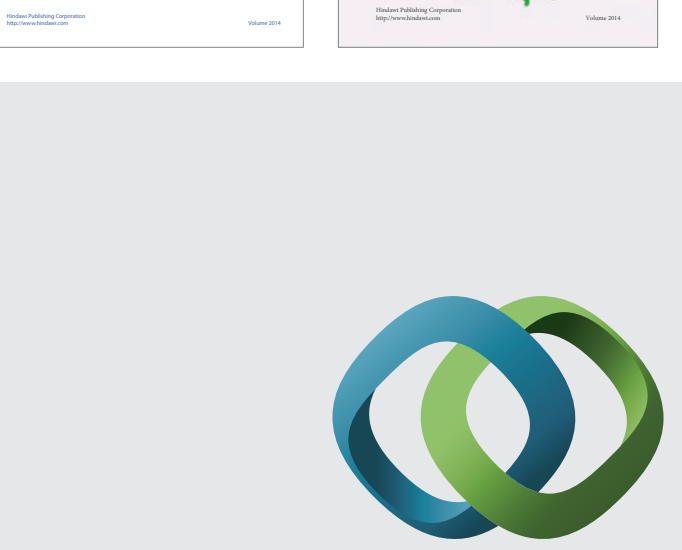

\section{Hindawi}

Submit your manuscripts at

http://www.hindawi.com
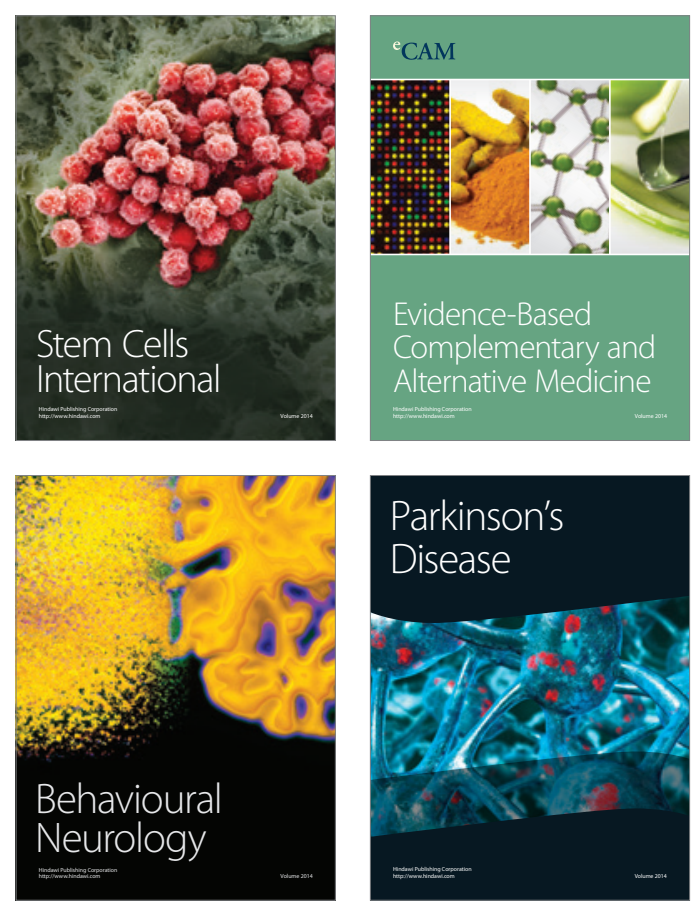

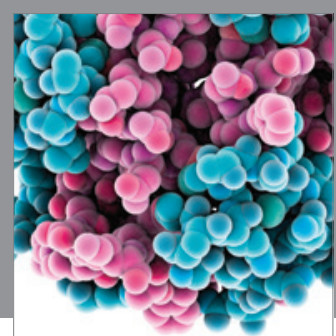

Journal of
Diabetes Research

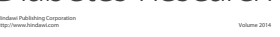

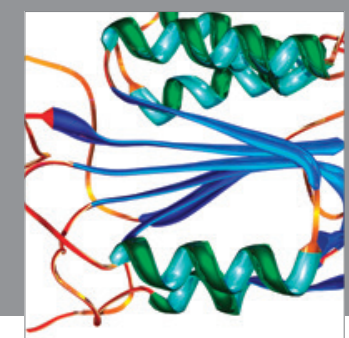

Disease Markers
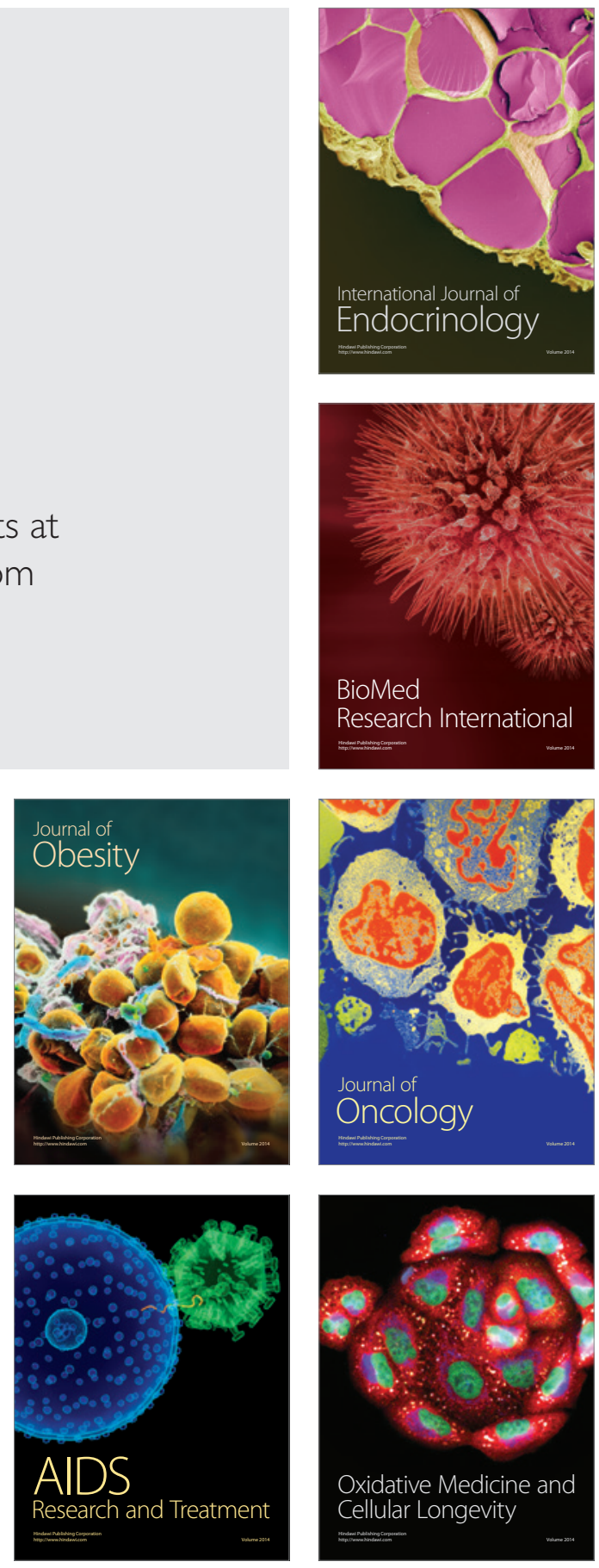